Revista Eletrônica em Gestão, Educação e Tecnologia Ambiental

Santa Maria, v. 20, n. 1, jan.-abr. 2016, p. 115-124

Revista do Centro de Ciências Naturais e Exatas - UFSM

ISSN : 22361170

REGET/UFSM

Revista Eletrônica em Gestão

Educação e Tecnologia Ambiental

\title{
Cadeia Produtiva do Mel: um estudo no município de Pau dos Ferros/RN
}

\author{
Honey Supply Chain: a study in Pau dos Ferros/RN \\ José Vivaldo Machado Fernandes Júnior¹, Napiê Galvê Araújo Silva² \\ ${ }^{1}$ Administrador, Especialista em Políticas Públicas e Desenvolvimento, UERN, Pau dos Ferros, RN, Brasil. \\ ${ }^{2}$ Economista, Mestre em Economia e em Políticas Públicas e Sociedade, Doutorando em Ciências Sociais, \\ Professor Assistente II, UFERSA, Mossoró, RN, Brasil.
}

\begin{abstract}
Resumo
O agronegócio do mel tem crescido consideravelmente nos últimos anos devido à grande procura da sociedade por produtos natura is. Deste modo, o presente trabalho teve como objetivo analisar a cadeia produtiva do mel na Associação Comunitária dos Agricultores Familiares do Perímetro Irrigado e Adjacências (ACAFPA) - Pau dos Ferros /RN. O tipo de pesquisa utilizado no estudo enquadra-se como exploratória, descritiva, documental e estudo de caso. Em relação à natureza dos dados, os métodos são qualitativos e quantitativos. O universo do estudo configura-se num total de 16 associados que participam ativamente das atividades da ACAFPA, sendo que o valor da amostra é de 13 pessoas. Definiu-se como instrumentos de coleta o formulário estruturado, a entrevista padronizada e a observação direta. Os tratamentos desses dados foram feitos através da estatística descritiva e da análise de conteúdo. Como resultados, apontam-se o aprimoramento do sistema produtivo apícola, devido à intervenção da ACAFPA no sentido de promover o desenvolvimento da apicultura, mas percebe-se que ainda existem limitações nos elos da cadeia produtiva. Por fim, visualiza-se que é preciso o aperfeiçoamento dos sócios através de cursos e que sejam tomadas medidas que permitam a padronização dos processos produtivos e o controle de qualidade do mel.
\end{abstract}

Palavras-chave: Cadeia produtiva, Agronegócios, Apicultura.

\begin{abstract}
The agribusiness honey has grown considerably in recent years from the high demand of society for natural products. Thus, the present work aims to analyze the supply chain of honey in the Associação Comunitária dos Agricultores Familiares do Perímetro Irrigado e Adjacências (ACAFPA) - Pau dos Ferros / RN.The type of research used to achieve the study is framed as exploratory, descriptive, documentary and case study. Concerning the nature of the data, the methods are qualitative and quantitative. The universe of study sets up a total of 16 members who actively participate in the activities of ACAFPA, and the value of the sample is 13 people. Defined as the collection instruments structured form, a standardized interview and direct observation and treatment of these data were made using descriptive statistics and content analysis. As a result, it was pointed out the improvement of beekeeping production system, due to the intervention of ACAFPA to promote the development of beekeeping, but realize that there are still limitations in the production chain. Finally, viewing, among other factors, the need to improve the applicant partners through courses and that measures are taken to enable the standardization of production processes and quality control of honey.
\end{abstract}

Key-words: Supply Chain, Agribusiness; Beekeeping. 


\section{Introdução}

A atividade apícola pode ser classificada como promissora considerando-se a expansão em que o mercado do mel encontra-se na atualidade. Entre tantos outros aspectos, a titulação justifica-se pelo fato de que, na última década (2001-2010), o Brasil alavancou sua produção em aproximadamente $60 \%$ (IBGE, 2012).

O cultivo de colmeias pode gerar diversos produtos que são úteis para o ser humano nos mais variados fins. Dentre estes, o mel é o mais conhecido e principal instrumento de comercialização. Além disso, existem ainda o pólen apícola, a cera de abelhas, o própolis, a geleia real e a apitoxina (SEBRAE, 2009).

No que diz respeito à agricultura no âmbito do Rio Grande do Norte, os números também se mostram positivos. Em 2009, o Estado potiguar conseguiu alcançar o $10^{\circ}$ lugar no ranking brasileiro. Tal posição na produção apícola é avaliada como um grande salto, considerando o significativo aumento da produtividade nos anos que compreendem 2001 a 2010, totalizando o crescimento de $217 \%$, ou seja, uma média de $27 \%$ ao ano, aproximadamente (IBGE, 2012).

Contudo, apesar da apicultura revelar-se favorável ao crescimento de quem a pratica, contribuindo expressivamente para a geração de emprego e renda, grande parte desta atividade é exercida em caráter informal. Paralelamente à intensificação deste setor de mercado, surge a carência em se obter mais informações, tecnologias e oportunidades de negócio. E, sem dúvidas, tais limitações podem vir a dificultar o agronegócio do mel.

Analisando por essa ótica, observa-se a necessidade de organizar os agentes de produção. Neste caso, as Associações apresentam-se como uma força unificadora capaz de auxiliar na cadeia produtiva, através do compartilhamento de vivências, troca de experiências de produção, aprimoramento técnico e inserção no próprio contexto social.

De acordo com esse pensamento, o presente trabalho teve como direcionamento estudar o agronegócio do mel na Associação Comunitária dos Agricultores Familiares do Perímetro Irrigado e Adjacências (ACAFPA) - Pau dos Ferros/RN, com ênfase nos elos da cadeia produtiva.

Entre outros aspectos, baseado no raciocínio em que se aponta o processo produtivo como um elemento primordial para garantir o êxito da apicultura, objetivou-se analisar os elos da cadeia produtiva do mel (comercialização, transformação e insumos), caracterizando-os e efetuando um mapeamento de toda a cadeia produtiva.

\section{Método da Pesquisa}

A presente investigação caracteriza-se, quanto aos fins, como exploratória e descritiva. Quanto aos meios, a pesquisa é documental e estudo de caso. Ainda, no que diz respeito à natureza dos dados, o método da pesquisa qualifica-se como quantitativo e qualitativo. (ROESCH, 2005).

$\mathrm{O}$ universo da pesquisa é composto pelos sócios ativos da Associação Comunitária dos Agricultores Familiares do Perímetro Irrigado e Adjacências (ACAFPA) - Pau dos Ferros/RN, correspondente a 16 pessoas que cotidianamente exercem suas atividades enquanto apicultores. Por conseguinte, a amostra foi absorvida de 13 sócios. O ano base da investigação é 2013 e a coleta de dados ocorreu em um período alternado que compreende os meses de janeiro a março de 2014 e de julho a setembro de 2014.

Para tanto, utilizou-se como instrumentos de coleta a entrevista padronizada (estruturada), o formulário estruturado e a observação direta (MARCONI E LAKATOS, 2008). A entrevista foi aplicada com a gestora da associação e os formulários estruturados com os demais sócios da instituição.

Na etapa de tratamento dos dados, onde foram analisadas as informações previamente coletadas nos formulários e observação direta, utilizou-se, para a configuração quantitativa, a estatística descritiva (CRESWELL, 2007). Por sua vez, para a apreciação do método qualitativo, houve a preferência de optar pela análise de conteúdo (RICHARDSON, 2010). 


\section{Resultados e Discussões}

A cadeia produtiva pode ser entendida como uma sequência de operações que conduzem à produção de bens, ou seja, um conjunto de elementos que interagem através de etapas consecutivas dentro de um processo produtivo. Neste meio, os diversos insumos sofrem algum tipo de transformação até a constituição de um produto final (bem ou serviço) e sua oferta ao mercado consumidor. O enfoque nas cadeias produtivas viabiliza a análise da dependência e relação dos elos dentro do sistema, como resultado da estrutura de mercado ou forças externas (OASHI, 1999).

Vale ressaltar que a teoria utilizada para o estudo foi a Analyse de Filière (ou Cadeia de Produção Agroindustrial - CPA), que tem como escopo de abordagem todos os atores envolvidos na produção, que vão desde o processamento e transformação de produtos, até a sua distribuição ao consumidor final. A abordagem divide-se em três possíveis partes: as cadeias produtivas em sua totalidade; o estudo de sua estrutura e relação dentro das cadeias; e o comportamento estratégico das firmas. (FREITAS et al., 2011).

Ao sintetizar diversas ideias iniciais na busca de conceituar a cadeia produtiva (Filière), Morvan (1988, p. 247) define tais elementos como caracterizadores de uma cadeia:

\footnotetext{
1. a cadeia de produção é uma sucessão de operações de transformação dissociáveis, capazes de ser separadas e ligadas entre si por um encadeamento técnico;2. a cadeia de produção é também um conjunto de relações comerciais e financeiras que estabelecem, entre todos os estados de transformação, um fluxo de troca, situado de montante a jusante, entre fornecedores e clientes.3. A cadeia de produção é um conjunto de ações econômicas que presidem a valoração dos meios de produção e asseguram a articulação das operações.
}

De modo geral, a Analyse de Filière pode ser subdividida em três seções que estão sujeitas à variação de acordo com o tipo de produto ou objetivo da análise. O primeiro segmento, a comercialização, diz respeito ao contato entre empresa/cliente, viabilizando o consumo e comércio dos produtos. $\mathrm{O}$ segundo, a industrialização, reúne os aspectos responsáveis pela transformação dos recursos em produtos finais. Em terceiro está a produção de matérias-primas, que, por sua vez, refere-se principalmente ao fornecimento de matérias-primas iniciais. Assim, Batalha et al. (2008, p. 7), relaciona os três macrossegmentos que propõem:

1. Comercialização:representa as empresas que estão em contato com o cliente final da cadeia de produção e que viabilizam o consumo e o comércio de produtos finais (supermercados, mercearias, restaurantes, cantinas, etc.). Podem ser incluídas neste macrossegmento as empresas responsáveis somente pela logística de distribuição.2. Industrialização:representa as firmas responsáveis pela transformação das matérias-primas iniciais em produtos finais destinados ao consumidor. O consumidor pode ser uma unidade familiar ou uma agroindústria.3. Produção de matérias-primas:reúne as firmas que fornecem as matérias-primas iniciais para que outras empresas avancem no processo de produção do produto final (agricultura, pecuária, pesca, piscicultura etc.).

Pontuando a importância das cadeias produtivas, é possível que a realização de estudos neste âmbito constitua-se enquanto uma medida fundamental para a estruturação de mecanismos capazes de prover informações sólidas para a tomada de decisões das instituições.

Submergindo no universo do agronegócio do mel, a apicultura encontra-se em franca expansão pelo fato de caracterizar-se enquanto uma atividade que possibilita a obtenção de diversos produtos que, além de possuírem um sabor que agrada grande parcela da população, estão relacionados à qualidade de vida, apresentam peculiaridades funcionais relacionadas à saúde, adentram na indústria de cosméticos e, ainda, está imiscuída em um viés sustentável, já que sua efetivação é ecologicamente correta. (SEBRAE, 2009).

Com o objetivo de visualizar os componentes da cadeia produtiva presentes no agronegócio do mel, dispõe-se a Figura 1 a seguir: 


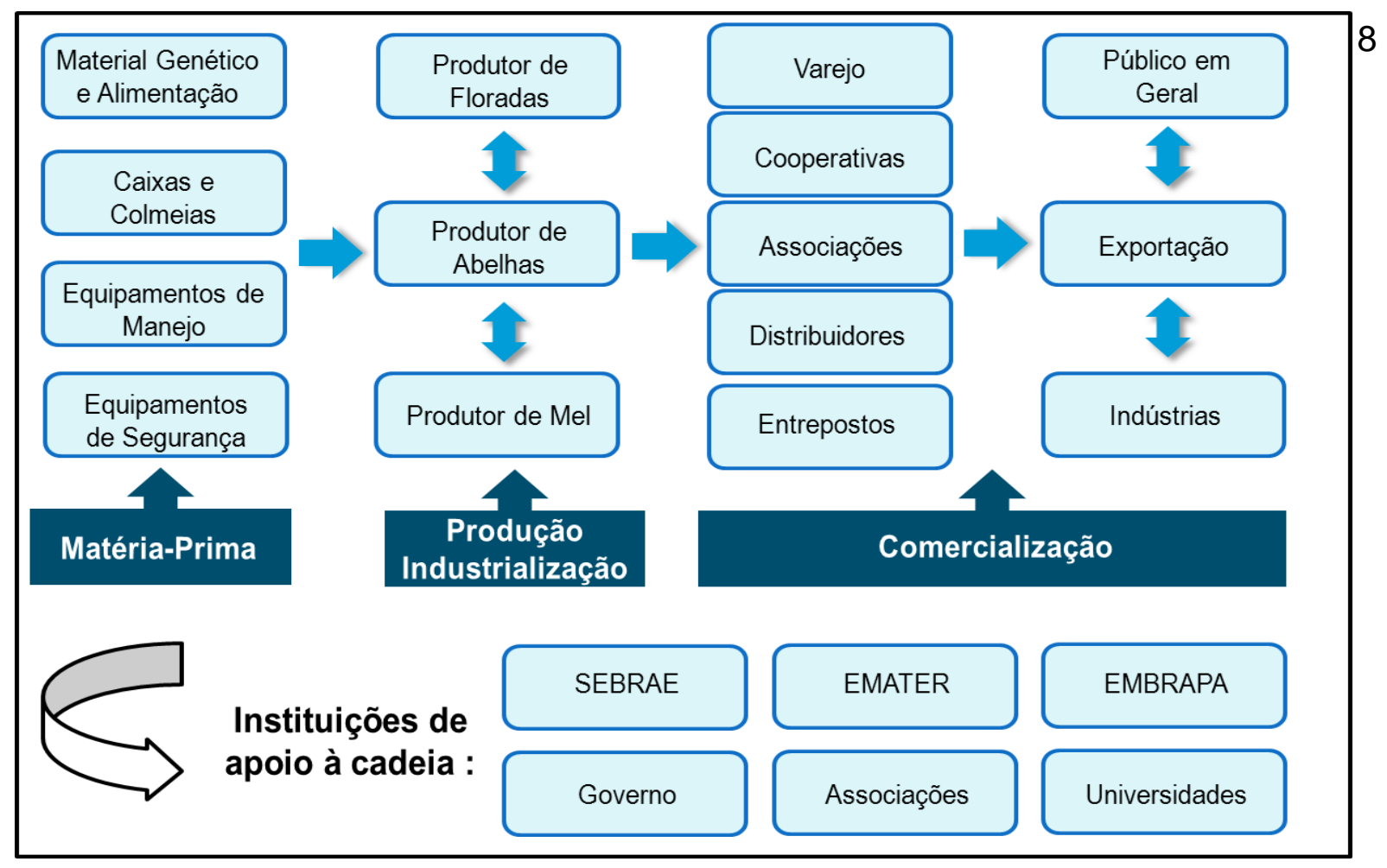

Figura 1 - Esquema geral da cadeia produtiva do mel.

Fonte: Adaptado de Lengler e Rathmann (2006).

A Figura 1 mostra um fluxograma da cadeia produtiva do mel de modo generalista, onde visualiza-seuma variedade de insumos, processos de transformação e possibilidades de distribuição e comercialização do produto em questão.

Contudo, ressalta-se que a predisposição dos agentes envolvidos nesse processo pode mudar de acordo com as atividades produtivas desenvolvidas e/ou interesses comerciais de cada organização que atue neste setor e, baseado nisso, utilizou-se esse modelo para a elaboração do mapeamento da cadeia na ACAFPA.

\section{1 Formulários}

Através do formulário aplicado com os 12 sócios ativos foi possível caracterizar de modo sistêmico os elos da cadeia produtiva do mel da ACAFPA, à luz da Analyse de Filière.

No que concerne ao elo da "comercialização", 100\% dos apicultores garantiram que o único produto comercializado é o mel, uma vez que, embora alguns associados produzam a cera, não a comercializam com o interesse de reutilizá-la em processos internos. Houve também unanimidade em relação aos principais compradores do mel fabricado pela ACAFPA, já que todos os associados vendem sua produção exclusivamente a um atravessador que praticamente monopoliza a comercialização local do mel, dificultando a negociação a fim de obter preços mais justos.

A submissão aos preços ditados pelo atravessador e a venda exclusiva a ele, carece, muitas vezes, da necessidade urgente de auferir renda que alguns associados possuem devido à situação econômica precária em que vivem. Deste modo, a desvalorização do produto é uma condicionante a se pagar para obter renda o mais rápido possível.

Neste contexto, os apicultores foram perguntados sobre o que eles acreditavam ser a principal dificuldade encontrada em relação à comercialização, onde 75\% dos sócios da ACAFPA expõem como maior entrave o preço baixo do mel. A grande maioria também avaliou como insatisfatória a divulgação dos produtos da associação e o consumo local.

Nota-se ainda que a capacidade produtiva da ACAFPA pode ser ampliada, caso sejam estabelecidas diretrizes que promovam a reestruturação de determinadas atividades com o intuito 
organizá-las e aperfeiçoa-las de maneira que fluam melhor e culminem em um desempenho mais eficaz.

Com relação ao elo "transformação", percebeu-se que há uma divergência de perfil entre os associados, pois alguns apresentaram uma constância de visitas acima de 5 vezes ao mês ao apiário, enquanto outros o faziam apenas 1 vez dentro do mesmo período.

Quanto ao número de colheitas efetivadas durante o ano, a maioria de $58 \%$ dos entrevistados disseram que, em média, ocorrem 3 colheitas. Todavia, deve ser relevado o fato de que essa quantidade de colheitas só é possível de acontecer caso haja um bom período chuvoso durante o ano, uma vez que este fator está diretamente relacionado à intensidade de produção das abelhas. Caso o ano em questão seja caracterizado por forte estiagem, a produção reduz consideravelmente.

Em seguida, a maioria dos membros da ACAFPA relataram que o beneficiamento do mel acontece na Casa do Mel da referida associação. Quanto a esse processo, aliado a outros componentes da produção, os sócios foram questionados se realizam algum tipo de padronização. Em resposta, predominantemente os associados relataram que não seguem um padrão e, tampouco, exercem o controle de qualidade adequado, baseando-se, muitas vezes, apenas pela coloração que o mel apresenta: quanto mais claro, maior qualidade.

No que concerne ao elo "insumos", a maioria dos apicultores disseram que a aquisição de abelhas é feita através de recursos próprios, porém, em anos anteriores aos da pesquisa, já ocorreram benefícios originários da ACAFPA, que conseguiu enxames de abelhas através dos seus esforços e as distribuiu entre os sócios. Embora em anos iniciais, pode-se perceber que a ACAFPA atuou positivamente no desenvolvimento produtivo dos associados, constatando-se que os beneficiou com abelhas e proporcionou o aumento da produção individual dos apicultores contemplados.

Quanto ao processo de aquisição de colmeias, percebeu-se que pouco mais da metadeas compram no comércio local. No entanto, um considerável percentual de $33 \%$ assegurou que tal matéria-prima é adquirida através de instituições, fator este que mais uma vez denota o caráter agregador da ACAFPA para os associados. Observou-se ainda que a maioria dos sócios possuem entre 2 e 3 apiários(lotes onde são instaladas as colmeias) e entre 40 e 60 colmeias.

Após serem indagados acerca do tipo de mão-de-obra predominante na extração do mel, $54 \%$ dos sócios afirmaram utilizar o trabalho familiar e sem remuneração, onde existem apenas acordos em relação a um pagamento de modo "informal", baseado nas necessidades de cada membro da família.

Em relação à aquisição de embalagens, a situação é semelhante ao que ocorre com as colmeias: um percentual de $92 \%$ as adquire no comércio varejista local. Contudo, destaca-se que, no caso de venda a atravessadores, geralmente as embalagens de comercialização são fornecidas por eles, sendo, portanto, necessário a compra, apenas, das embalagens de armazenamentopróprio do mel.

Em seguida, dois questionamentos obtiveram unanimidade de respostas no que tange à caracterização do elo "insumos" durante a pesquisa: o primeiro índice de $100 \%$ corresponde ao percentual de sócios que já participaram de algum tipo de curso ou treinamento por intermédio da ACAFPA. Os entrevistados apontaram que os cursos dos quais participaram referem-se, principalmente, a orientações básicas da apicultura; manejo com os apiários; e reconhecimento da abelha rainha nas colmeias.

A segunda indagação diz respeito a qual produto apícola é mais produzido, onde $100 \%$ dos apicultores afirmaram que é o mel. Em pormenores, deste percentual $67 \%$ produzem apenas o mel e outros $33 \%$ conseguem produzir, além do mel, a cera de abelha. Todavia, mesmo os associados que fabricam a cera, não a comercializam, pois esta é sempre reutilizada em processos internos da instituição.

Vale salientar que a quantidade de mel produzida pela grande maioria dos associados no ano de 2011, variou entre 1000 e 1999 (kg) de mel e que os sócios acreditam que houve o crescimento da produção em relação a anos anteriores. 


\subsection{Entrevista}

Com base na entrevista realizada com a gestora da ACAFPA, foi possível perceber que ele possui intimidade com a atividade desde a infância, onde ajudava a família com o cultivo de feijão e outros tipos de alimentos que faziam parte do consumo familiar diário e tomou a iniciativa de ingressar na apicultura para incrementar a renda.

Desde a fundação da associação, que data de 15 de julho de 2005, a maioria dos sócios já participaram de cursos, principalmente até o ano de 2009, pois há aproximadamente dois anos a ACAFPA encontra-se inativa em relação a este tipo de atividade, embora reconheça sua importância para o aperfeiçoamento da produção.

Entre os principais cursos estão o "Curso Básico de Apicultura" e o "Como Lidar com o Apiário", onde, este último, oferta conhecimentos que permitem reconhecer a abelha rainha dentro da colmeia; como retirá-la sem prejudicar a colmeia; e qual o tipo de folhagem mais indicada para produzir a fumaça na hora da extração do mel. Neste caso, a procura por cursos indicia o interesse em aprimorar tecnicamente os sócios para que estes possam desenvolver suas atividades de modo mais eficaz com base nos conhecimentos adquiridos.

Os principais tipos de flores utilizados para a produção do mel na ACAFPA, segundo a gestora, é a do "Marmeleiro" (Croton sonderianus) e outra regionalmente conhecida como "Cabeça-Branca" (Borreria capitata) que são nativas da região, nascendo de modo natural. $\mathrm{O}$ único cuidado efetuado é relativo ao aparecimento de ervas daninhas ou qualquer outro tipo de vegetação invasora que possa prejudicar as abelhas. Entre tantas, destaca-se a planta conhecida como "Nim" (Azadirachta Indica) que possui propriedades venenosas nocivas ao cultivo de abelhas.

A gestora relata que a maioria dos associados se utilizam do trabalho familiar e sem remuneração, onde existem apenas acordos em relação a um pagamento de modo informal a partir da necessidade de cada um, como: uma roupa no fim do mês; a aquisição de um eletrodoméstico; o pagamento da parcela de um móvel; etc.

No início da associação, os materiais como colmeias e embalagens foram adquiridos com recursos próprios, porém, após dois anos, cada sócio foi beneficiado pelo Governo Federal com dez colmeias, o que intensificou a prática da apicultura. O depósito de armazenamento também foi proveniente dos esforços em conjunto, contudo, as embalagens para comercialização são adquiridas com recursos próprios, quando não ofertadas pelo comprador e a maioria dos materiais são obtidas no mercado local.

Quanto ao prazo de validade de estocagem do mel, a gestora da ACAFPA afirmou que o ideal é que não ultrapasse um período de 06 meses a 1 ano e que geralmente esse intervalo de tempo não é excedido na ACAFPA. Caso esse período seja extrapolado, a coloração do mel pode escurecer, afetando sua qualidade e deixando-o com um sabor mais acentuado. Percebeu-se, neste ponto, que muito do que a ACAFPA entende sobre qualidade do mel, refere-se, apenas, à sua coloração, onde o SEBRAE (2009) apresenta que, quanto mais clara for a coloração do mel, maior qualidade e suavidade no sabor. Contudo, é preciso ressaltar que o cuidado deve permear todo o processo produtivo, já que a coloração é apenas um dos diversos fatores analisados para classificar a qualidade do mel.

Com base na literatura do agronegócio apresentada por Davis e Goldberg (1957), visualiza-se que a soma de operações de produção e distribuição de suprimentos, englobando o armazenamento, processamento e distribuição de produtos, estão presentes no cotidiano da ACAFPA. Acerca do detalhamento do processo produtivo na associação, a diretora diz que, na época da colheita, é verificado se as colmeias dos apiários estão cheias. Em caso positivo, utiliza-se o "fumegador" e retirase as caixas com "melgueiras", inserindo-as em sacos plásticos de nylon para que sejam transportadas até a Casa de Mel. Após isso, o apicultor higieniza-se e coloca as melgueiras na "mesa desoperculadora" onde é retirado o excesso de cera. Em seguida, coloca-se as melgueiras na "centrífuga" onde devem permanecer por aproximadamente cinco minutos, para que o mel escorra, sendo filtrado por uma peneira e caindo em um depósito que fica na parte inferior da centrífuga. Para finalizar a extração, o mel é colocado no "decantador" por 48 horas. Esse período serve para retirar as 
impurezas do produto e equilibrá-lo com a temperatura ambiente, antes de envasar o mel para a comercialização.

A partir dos dados obtidos na resposta, é possível efetivar o que sugere a Analyse de Filière: analisar um recorte dentro do processo produtivo da associação, um intervalo que contemple tanto a sucessão de processos de transformação, quanto a descrição de tal processo. (FREITAS et al., 2011).

Quanto ao beneficiamento, segundo a diretora da ACAFPA, o mel é pesado e distribuído em baldes. Caso um apicultor tenha extraído $1000(\mathrm{Kg})$ de mel e outro $700(\mathrm{Kg})$, é feito uma triagem acerca da qualidade do mel com base na coloração: se ambos possuírem colorações idênticas, são misturados. Em caso contrário, são depositados em diferentes recipientes. Por sua vez, o secretário da associação é o responsável por acompanhar o controle de saída do mel, garantindo que cada associado se beneficie apenas daquilo que produziu e zele pelo material da associação. Tal controle é exposto nas reuniões mensais da ACAFPA, onde percebe-se que são realizadas de modo extraoficial, sem a confecção de um relatório ou qualquer outro tipo de documento que formalize a referida operação.

Embora exista o esclarecimento acerca do processo produtivo, com base nas palavras da gestora, não há uma padronização a ser seguida de modo rígido. Os apicultores possuem autonomia para produzirem o mel à sua maneira, desde que prezem pela higiene, não extraviem o material da associação e tampouco afetem a vida das abelhas de algum modo.

A entrevistada acredita ainda que as principais dificuldades encontradas no processo de produção e transformação do mel estão ligadas à falta de conhecimento prático e teórico dos sócios. A maioria daqueles que possuem conhecimento técnico não o aplicam completamente à prática. Para tanto, $\mathrm{o}$ ideal seria o aperfeiçoamento dos associados através de cursos que contemplem as diversas áreas na qual a apicultura é subdividida.

Ao ser questionada sobre o que acreditava ser a medida mais correta para garantir a qualidade do mel, ela diz que essa questão é complicada porque o próprio conhecimento sobre a qualidade ideal do mel é limitado. $\mathrm{O}$ único processo de qualidade utilizado é a decantação e o modo empírico de separar o mel mais claro do mais escuro. Deste modo, considera-se pertinente, inicialmente, investir em algum curso que mostre todas as regras básicas necessárias para adquirir o selo de qualidade do mel. Assim, por mais resistente que os associados possam ser, a diretora acredita que mudariam a opinião e procurariam melhorar o modo como produzem. A entrevistada ressalta ainda que é preciso adaptar o espaço físico da Casa de $\mathrm{Mel}$, mas faltam recursos financeiros.

Em relação às dificuldades na comercialização, a diretora da ACAFPA crê que a desvalorização do produto na região é um empecilho. Também é considerado um fator desfavorável a presença de atravessadores que ditam o preço do mel na região. Como tentativa de solucionar o problema, acredita-se que caso todos os sócios produzissem no mesmo período, seria possível unificar a produção e vender o mel diretamente a uma cooperativa ou indústria que trabalhe com o produto. Deste modo, seria possível negociar a um preço mais satisfatório. No ano de 2011, o preço médio de venda foi de $\mathrm{R} \$ 3,20$ por $\mathrm{kg}$, o que é considerado um preço regular, tendo em vista que o preço mais alto alcançado até hoje foi de $R \$ 3,80$ por kg e o mínimo correspondeu a $R \$ 2,90$. Os contatos para a venda são feitos via telefone e há dois anos a associação comercializa o mel para o mesmo atravessador.

\subsection{Mapeamento da cadeia produtiva do mel da ACAFPA}

Diante do exposto, entendendo a cadeia produtiva (Filière) sob a ótica de Morvan(1988), como uma sucessão de operações dissociáveis, que podem ser separadas e ligadas por um encadeamento técnico e pautado na relação de Batalha et al. (2008), que classifica os elos da cadeia produtiva em comercialização, industrialização (transformação) e matérias-primas (insumos), pode-se fazer uma correlação do que foi observado na ACAFPA com as teorias em questão. Para tanto, no próprio discurso da gestora e nos dados obtidos através da aplicação dos formulários com os sócios, é perceptível que existem falhas dentro de cada elo da cadeia produtiva do mel da associação.

Após conhecer o processo produtivo do mel da ACAFPA, é possível obter uma noção sistêmica da cadeia produtiva, o qual é esquematizado na Figura 2, a seguir: 


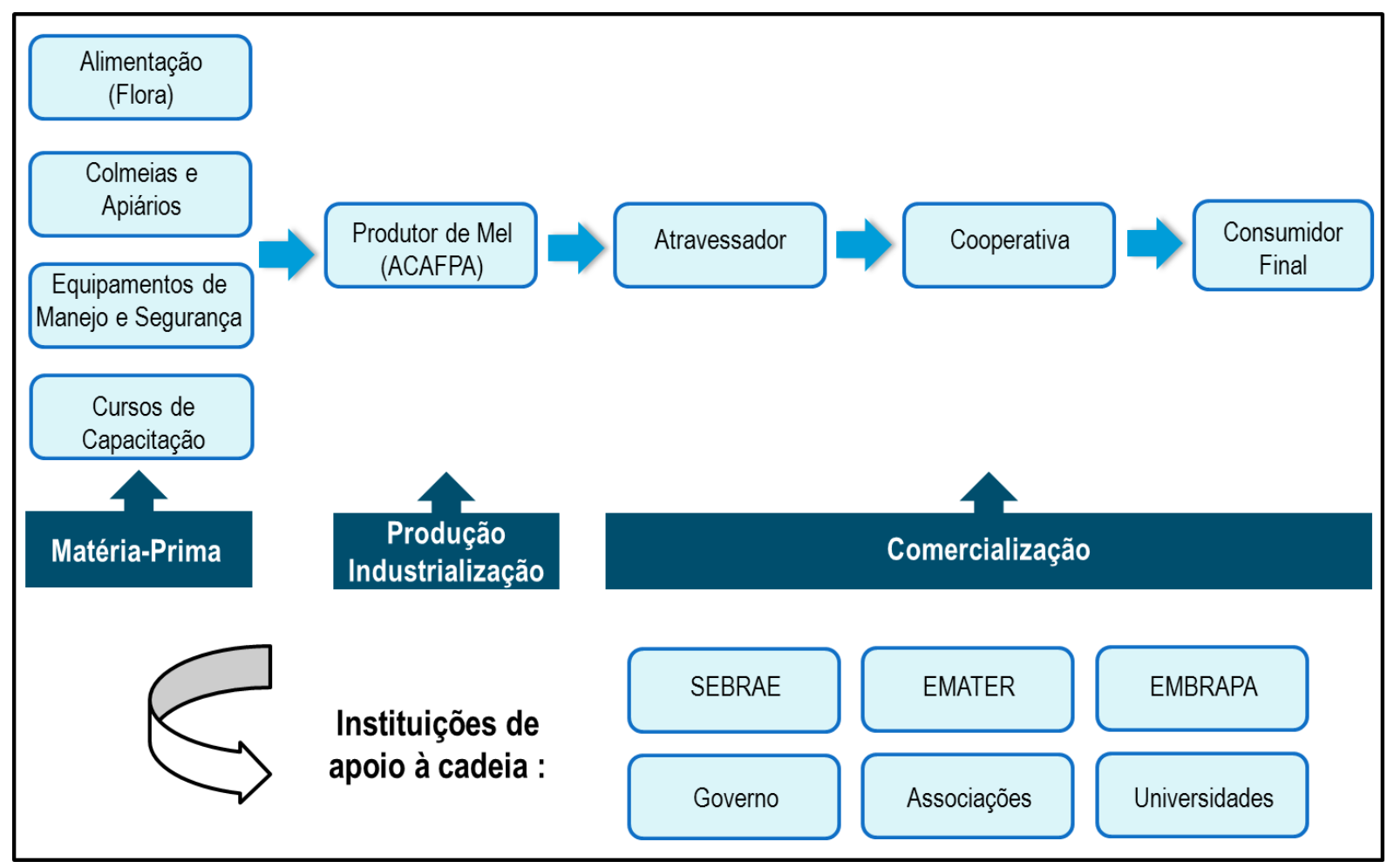

Figura 2 - Cadeia produtiva do mel da ACAFPA.

Fonte: Pesquisa de Campo (2012).

Durante a pesquisa foi possível identificar que existem limitações inseridas na cadeia produtiva do mel da ACAFPA, mais especificamente nos três elos, que se classificam em: comercialização, transformação e insumos.

Quanto à comercialização, nota-se que há o monopólio por parte de um agente atravessador, que dita o preço de venda do mel e limita a rentabilidade dos associados, que acabam penalizados pelo baixo preço do produto. Os associados não procuram comercializar junto ao mercado varejista ou em vendas diretas em feiras livres, tampouco unem a produção individual para tentar vender o mel acumulado diretamente a uma cooperativa ou indústria que utilize o referido produto como matériaprima, o que também seria viável para eliminar a presença do atravessador e ampliar o mercado com possibilidades de vender o mel a um preço mais satisfatório. Atrelado a esse fator, está a desvalorização do produto na região, já que a população local ainda não alertou para os benefícios advindos do mel (SEBRAE, 2009) e geralmente enxerga o doce líquido apenas como um produto medicinal, não o adicionando à dieta alimentar cotidiana.

No que tange ao processo de transformação do mel, inerente ao segundo elo da cadeia, os obstáculos principais estão relacionados à padronização das atividades no processamento do mel, beneficiamento dos apicultores e o controle de qualidade existente nesse processo. Sobre a padronização, vê-se que não há um conhecimento aprofundado acerca do termo e que, muito embora de modo inconsciente, exista um modelo que é seguido, ainda há vários desvios de conduta que impossibilitam caracterizar os processos como sendo padronizados de maneira adequada e comum a todos os associados da ACAFPA. No controle de qualidade, também fica claro o conhecimento limitado, já que os únicos procedimentos realizados que estão relacionados a esta atividade restringem-se à decantação e à separação do mel através da coloração.

Em relação à matéria-prima utilizada pela associação, observa-se que grande parte é adquirida com recursos próprios de cada sócio e geralmente no mercado local, sem maiores pesquisas de preço. A flora utilizada para alimentar as abelhas que influencia na qualidade do mel, aparentemente, é 
satisfatória. Além disso, os associados merecem passar por melhores capacitações, embora seja reconhecido o esforço da ACAFPA para que isso aconteça.

É perceptível, também, que algumas instituições atuam no apoio à cadeia produtiva, entre elas estão: o Governo Federal; demais associações que se relacionam com a ACAFPA; as Instituições de Ensino Superior (IES) que desenvolvem recorrentes pesquisas na área; e organizações como SEBRAE, EMBRAPA E EMATER.

\section{Conclusões}

A partir do levantamento feito por meio desta pesquisa, acredita-se que foi atendido o objetivo geral do trabalho de analisar os elos da cadeia produtiva da ACAFPA e efetuar um mapeamento de toda a cadeia produtiva.

Para tanto, de fato, foram observadas limitações dentro dos elos da cadeia produtiva da ACAFPA e é mister fazer um breve resgate dos principais pontos evidenciados em cada um:

\section{1 Caracterização dos elos da cadeia produtiva do mel na ACAFPA:}

No que diz respeito ao elo "comercialização", releva-se a venda exclusiva a um atravessador e a consideração do preço baixo do mel como principal variável prejudicial à comercialização. Ressalta-se também a avaliação do consumo local e divulgação dos produtos da ACAFPA como fracos. Na "transformação", sobressaem-se características relacionadas à ausência de padronização no processo produtivo e do controle de qualidade na produção do mel. Quanto aos "insumos", destacam-se os fatos da maioria da matéria-prima utilizada pela ACAFPA ser comprada no mercado local, sem consultas a fornecedores de outra região; a atividade ser predominantemente familiar e sem remuneração; e o conhecimento teórico limitado dos sócios.

\subsection{Mapeamento da cadeia produtiva do mel na ACAFPA:}

Nesse quesito, o delineamento da cadeia produtiva do mel na associação permitiu compreender melhor as relações entre os elos que a compõem e, deste modo, aprofundar a aplicabilidade teórica utilizada no estudo (ver Figura 2, p. 08). A esquematização da cadeia produtiva viabiliza que a análise dos elos flua de maneira mais nítida e, consequentemente, oferta mais vantagens à instituição na qual o estudo se desenvolveu, possibilitando o fortalecimento de suas atividades.

Diante dos fatores supracitados, compreende-se que o estudo logrou êxito em seu desenvolvimento. De modo geral, foi possível analisar os elos da cadeia produtiva do mel pautado nas premissas da Analyse de Filière, que, sobretudo, revela que os elos que compõem uma cadeia podem ser estudados separadamente e, assim, torna-se mais provável a identificação das suas limitações, bem como possibilita tomadas de decisões eficazes para eliminar tais entraves.

\section{Agradecimentos}

Agradeço aos revisores da revista REGET/UFSM pelas valorosas e pacientes orientações referentes às adequações do exemplar; aos colaboradores da edição de modo geral; e ao meu professor, Ms. Napiê Galvê Araújo Silva, pelas conduções e ajustes necessários ao aperfeiçoamento desta pesquisa.

\section{Referências}

BATALHA, M. O. et al. GEPAI: Grupo de Estudos e Pesquisas Agroindustriais. Gestão agroindustrial. $3^{\mathrm{a}}$ ed. São Paulo: Atlas, 2008. 
CRESWELL, J. W. Projeto de Pesquisa:métodos qualitativo, quantitativo e misto / Jonh W. Creswell; trad. Luciana de Oliveira da Rocha. Porto Alegre: Artmed, 2007.

DAVIS, J. H.; GOLDBERG, R.A. A concept of agribusiness. Boston: Harvard University, 1957.

FREITAS, J. B. et al. A Teoria de Filière aplicada à cadeia produtiva do milho em assentamento rural no Nordeste do Brasil. In: VIII SIMPÓSIO DE EXCELÊNCIA EM GESTÃO E TECNOLOGIA.- SEGeT. 2011, Rio de Janeiro. A Teoria de Filière aplicada à cadeia produtiva do milho em assentamento rural no Nordeste do Brasil. Rio de Janeiro: SEGeT, 2011.

IBGE. Instituto Brasileiro de Geografia e Estatística. 2012. Disponível em:

<http://www.ibge.gov.br/home/>.Acesso em: 09 de março de 2012.

LENGLER, L.; RATHMANN, R. Assimetria de relacionamentos na cadeia apícola do Rio Grande do Sul. Revista FAE, Curitiba, v. 9, n. 2, p. 51-62, jul./dez. 2006.

MARCONI, M. A.; LAKATOS, E. M. Técnicas de pesquisa. 7aㅗ ed. São Paulo: Atlas, 2008.

MORVAN, Y. Fondements d'économie industrielle. Paris: Economica, 1988.

OASHI, M. da C. G. Estudo da cadeia produtiva como subsídio para a pesquisa e desenvolvimento do agronegócio do sisal na Paraíba. 1999. Tese (Doutorado) - Universidade Federal de Santa Catarina, Florianópolis, 1999.

RICHARDSON, R. J. Pesquisa social: métodos e técnicas. 3 ed. São Paulo: Atlas, 2010.

ROESCH, S. M. A. Projetos de estágio e de pesquisa em administração: guia para estágios, trabalhos de conclusão, dissertações e estudos de caso. 3 ed. São Paulo: Atlas, 2005.

SERVIÇO BRASILEIRO DE APOIO ÀS MICRO E PEQUENAS EMPRESAS (SEBRAE). Apicultura: uma oportunidade de negócio sustentável. 2009. Disponível em: <http://www.ba.sebrae.com.br>. Acesso em: 03 de março de 2012. 